\title{
An algorithm for the assignment of sentence accents in Dutch
}

\author{
Heleen Hoekstra
}

Utrecht University/UiL OTS

\section{Introduction}

For a theory of sentence accent ${ }^{1}$ to be suitable, if only in principle, for use in a textto-speech system, ${ }^{2}$ it should preferably

- have the nature of an algorithm,

- predict all accents (instead of 'nuclear/main/primary' accent only),

- do so merely on the basis of the text itself (i.e. without human intervention),

- deal with lexical and contextual deaccenting,

- allow for a simple treatment of well-defined exceptions and alternative accentuations.

In this paper SAiD (Sentence Accents in Dutch) is presented: an algorithm for the assignment of sentence accents in Dutch that is intended to meet the above requirements.

\section{Current views of sentence accent}

Virtually all modern phonological theories of sentence accent can be considered versions of what Ladd (1996) calls the 'structure-based focus-to-accent (FTA) approach'. Within this approach, the problem of sentence accent assignment may be stated as follows: where do we place accent, given focus? (Ladd 1996). Here, 'focus' is essentially used as a linguistic primitive, indicating the part of an utterance that can intuitively be considered to express 'new' information (as opposed to 'given'). The concept is poorly defined in fact, but for our present purpose the intuitive notion of focus suffices.

A crucial distinction within the structure-based FTA approach is the one between 'broad' and 'narrow' focus, which is illustrated by the following example: 
(1) a thousand dollars

a. a thousand DOLLARS

b. a THOUSAND dollars

c. a THOUSAND DOLLARS

It is argued that the accent on dollars in (a) can be interpreted as signaling either narrow focus (as in: not a thousand GUILDERS - a thousand DOLLARS) or broad focus (as in: A: What did you pay for that television set? B: A thousand DOLLARs), whereas the accent on thousand in (b) only allows for a narrow focus reading (as in: not a HUNDRED dollars - a THOUSAND dollars). In fact, and this is generally acknowledged, (a) can only get a broad focus reading if it is pronounced in a hasty and matter-of-fact way. If not, there will be an additional, 'secondary', accent on thousand, as in (c). The reason that the accent on dollars in (c) is analysed as primary and the one on thousand as secondary is that, in order to signal broad focus, the accent on dollars cannot be missed, whereas the one on thousand can, under certain conditions. In this view, then, the primary accent is the one that signals broad focus.

Accordingly, the key question within the structure-based FTA approach is: given broad focus, where does the primary accent land? Each secondary accent can then be defined as the primary accent of one of the utterance's constituent parts, but of course this does not answer the question of which constituents qualify for an accent and which do not. We will come back to this issue later on.

\section{SAiD}

\subsection{The idea}

An algorithm for the assignment of sentence accents that is intended to be usable as a component of a text-to-speech system cannot depend on human intervention to be told which parts of an utterance have to be 'focused' or accented, but has to assign accents merely on the basis of the text itself. The hypothesis behind SAiD is that this is indeed possible, because the position of sentence accents in Dutch is essentially a surface-syntactic matter. ${ }^{3}$ The only additional information the algorithm needs is deaccenting information: which parts of the utterance must be deaccented, either inherently (e.g. $z e, z^{\prime} n$, d'r, which are the inherently deaccented versions of $z i j$ ('she'/'they'), zijn ('his') and haar ('her'), respectively) or on the basis of the preceding context. SAiD assumes that inherently deaccented words are marked as such in the lexicon and that contextual deaccenting is taken care of by a discourse grammar, which determines the anaphoric relations between (parts of) an utterance and its preceding context on the basis of the structure of the text.

As a consequence of the hypothesis that sentence accents can be assigned merely on the basis of syntactic structure enriched with deaccenting information, 
the phonological notion of focus, as it is used within the structure-based FTA approach, has no role to play in SAiD. Accordingly, the question to be answered in relation to sentence accent assignment becomes: given that an $(y)$ utterance must be accented, where do we place accent?

\subsection{The algorithm}

SAiD takes as input X-bar S-structures that were pruned in order to avoid nonbranching nodes. To such a, strictly binary branching, structure a default metrical labeling is assigned. On the basis of this default weak-strong labeling ( $\omega$ - $\varsigma$ labeling) in combination with deaccenting information (coming from the lexicon and from the discourse grammar) the actual weak-strong labeling (w-s labeling) is determined, on the basis of which accents are assigned.

Schematically:

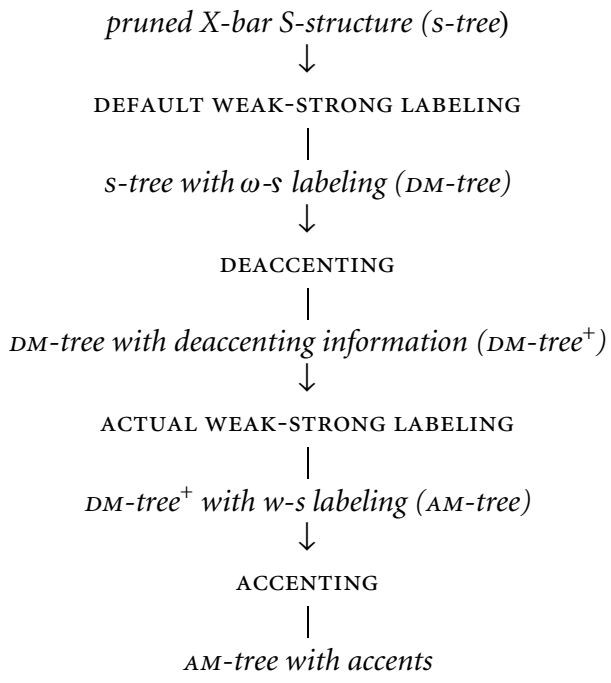

In this schema $s$-tree, $D M$-tree, $D M$-tree ${ }^{+}$and $A M$-tree are variables, whose names can be read as syntactic, default metrical, enriched default metrical, and actual metrical tree, respectively.

The four rules that make up SAiD are defined as follows:

Default weak-strong labeling

- heads $\left(\mathrm{X}^{0} \mathrm{~s}\right)$ are weak-by-default $(\omega)$,

- $\quad X^{1} s$ are strong-by-default ( $\varsigma$ ),

- adjuncts are weak-by-default $(\omega)$,

- the sister of a $\omega$ node is $\zeta$, the sister of a $\varsigma$ node is $\omega$. 
This rule implies that complements (being sisters of $\mathrm{X}^{0} \mathrm{~s}$ ) are strong-by-default and specifiers (being sisters of $\mathrm{X}^{1} \mathrm{~s}$ ) are weak-by-default.

\section{Deaccenting}

For each node $\mathrm{X}, \mathrm{X}$ is deaccented if

a. $\mathrm{X}$ is marked $[-\mathrm{A}]$ or

b. both nodes dominated by $\mathrm{X}$ are deaccented or (upward passing)

c. the node immediately dominating $\mathrm{X}$ is deaccented. (downward passing)

Though this rule is briefly called Deaccenting, the only thing it actually does is stating that a node is deaccented if it is marked as such (in the lexicon or by the discourse grammar), and passing the attribute upward or downward.

Actual weak-strong labeling

Given two sister nodes $X_{\omega}$ and $Y_{c}$, then $X$ is weak and $Y$ is strong, unless

$\mathrm{Y}$ is deaccented and $\mathrm{X}$ is not, in which case $\mathrm{Y}$ is weak and $\mathrm{X}$ is strong.

Normally, default weak becomes actually weak and default strong becomes actually strong. Only if a default strong node is deaccented whereas its (default weak) sister is not, default strong becomes actually weak and default weak actually strong.

\section{Accenting}

For each node $\mathrm{X}, \mathrm{X}$ is accented if $\mathrm{X}$ is not deaccented and

a. $\mathrm{X}$ is the top node or

b. $\mathrm{X}$ is weak and a maximal projection, or

c. $\mathrm{X}$ is strong and the node immediately dominating $\mathrm{X}$ is accented.

This rule reflects the main idea behind SAiD: in Dutch at least, accenting is a surface-syntactic affair, whereas deaccenting is a matter of context. More specifically, (a) states that any utterance (full sentence or other) must be accented, (b) that each maximal projection (XP) is a candidate for accent, though only in the case of weak XPs this has to be stated explicitly, as the accenting of strong XPs is taken care of by (c), the recursive part of the rule, which eventually assigns accents to words by following down a path of strong nodes, starting at the top node or at a weak XP. A weak XP thus functions as the upper boundary of the scope of an accent, as does the top node.

SAiD thus consists of four ordered rules. The composition of the algorithm shows similarities with that of Pros2 (Dirksen and Quené 1993), which is meant to be an improved version of Baart's algorithm (Baart 1987). As regards content, however, there are considerable differences. Firstly, Pros2 takes as input rather idiosyncratic syntactic structures, produced by a grammar that was designed specifically for the purpose of accent assignment, whereas SAiD assigns accents to $\mathrm{X}$-bar structures. Secondly, focus does not play a role in SAiD. And finally, SAiD's Default weak-strong labeling differs essentially from its equivalent in the Baart/ Pros2 approach, as will become clear in Section 5. 


\subsection{Examples}

The following examples should give the reader an idea of how SAiD works. First the example utterances are listed, then the corresponding X-bar structures are shown, together with the outputs of the different modules of SAiD.

(2) twee repen witte chocola two bars white chocolate 'two bars of white chocolate'

(3) chocola met hele hazelnoten chocolate with whole hazelnuts 'chocolate with whole hazelnuts'

(4) we zijn vroeg vertrokken we have early left 'we left early'

(5) a. Jan heeft een meisje gezoend Jan has a girl kissed 'Jan kissed a girl'

b. Jan heeft d'r gezoend Jan has her kissed 'Jan kissed her'

The trees on the left are the X-bar structures, the ones in the middle the result of pruning and subsequent Default weak-strong labeling and Deaccenting ( $D M-$ tree $^{+}$ in the schema), and the ones on the right the output of subsequent Actual weakstrong labeling and Accenting (AM-tree with accents in the schema).

(2)

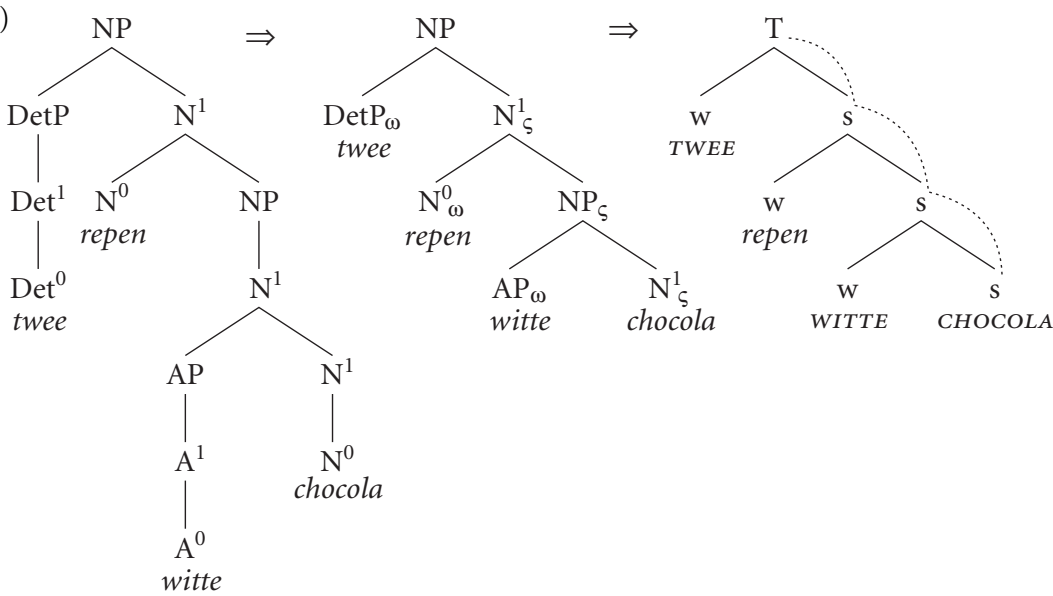


The accents on twee and witte come from the weak DetP and AP, respectively. The one on chocola comes from the top node $(\mathrm{T})$, via a chain of strong nodes (the dotted lines). Repen remains unaccented, being weak and not an XP.

(3)

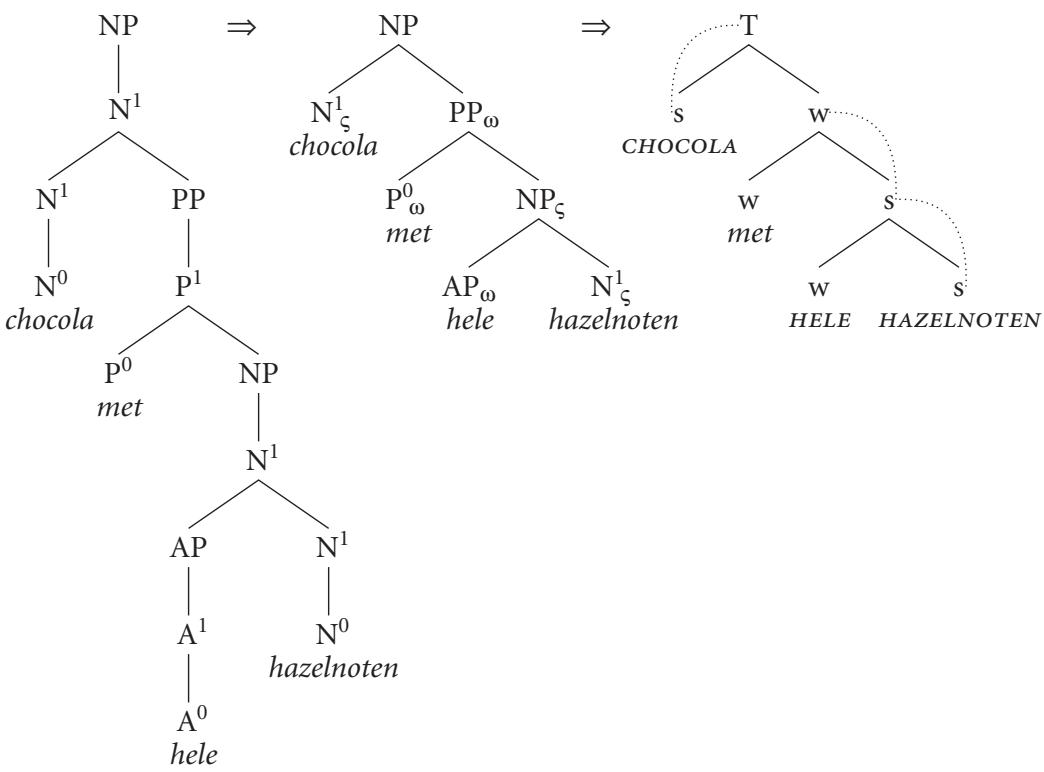

The accent on chocola comes from the top node, the one on hele from the weak AP, and the one on hazelnoten from the weak PP. Met remains unaccented, being weak and not an XP. The reader is invited to check the examples (4) and (5a) for himself.

(4)

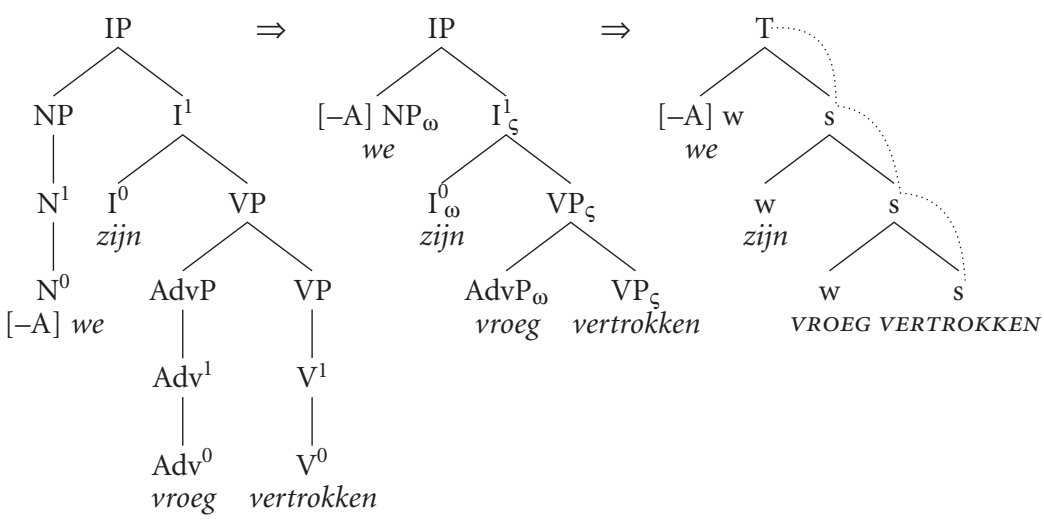


(5) a.

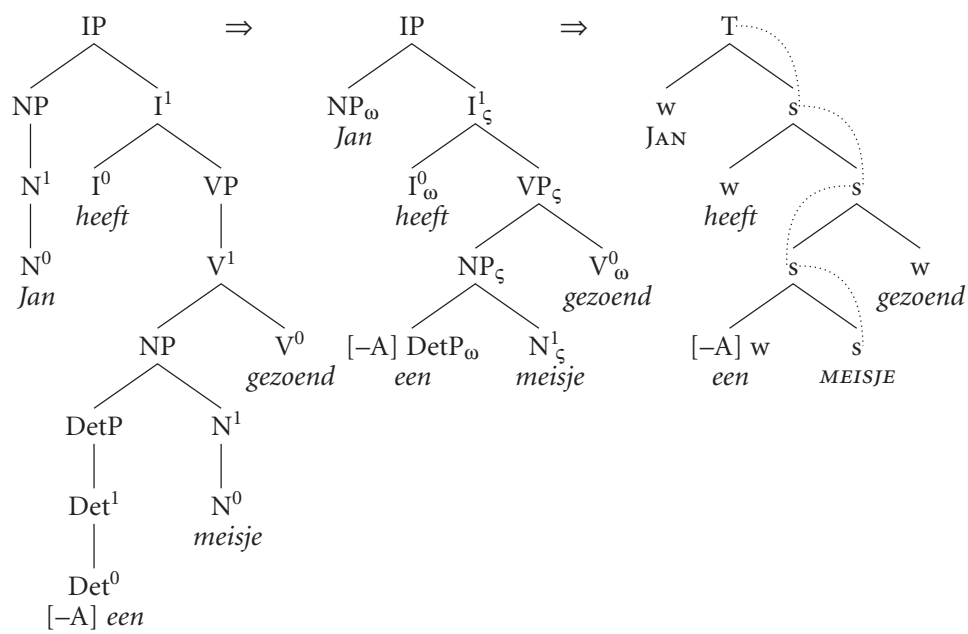

b.
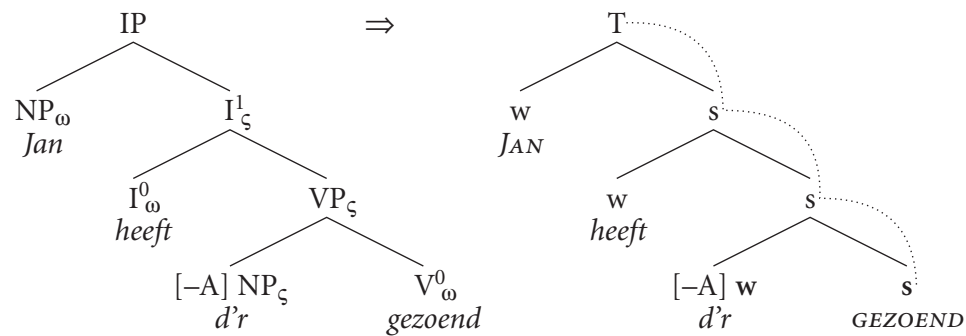

Because the complement NP ( $d^{\prime} r$ ) in (5b) is deaccented (and $\mathrm{V}^{0}$ is not), Actual weak strong labeling translates the default order $\varsigma-\omega$ into the actual order $\mathrm{w}-\mathrm{s}$. The effect is that $\mathrm{V}^{0}$ is now strong and therefore gezoend gets an accent from the top node. Note that deaccenting only leads to accent shift if the deaccented node is strong-bydefault (and its sister node is not deaccented), because only in that case is $\varsigma-\omega$ translated into $\mathrm{w}$-s. The deaccenting of a default-weak node, like the subject NP $(w e)$ in (4) and the DetP (een) in (5a), does not lead to accent shift.

\section{Discussion}

\subsection{Primary versus secondary accent}

What SAiD says, in fact, is that every constituent in an utterance that is a maximal projection is a candidate for accent, thus answering the question, raised at the end of Section 2, of which constituents of an utterance qualify for secondary accents. Of course, this answer raises a new question: what, if any, is the status of the primarysecondary distinction made for sentence accents, according to SAiD?, the answer 
given within the structure-based FTA approach, that primary accent is the one that signals broad focus, being meaningless within the SAiD approach. The obvious answer is that primary accent is the accent that 'comes from' the top node. The problem of this definition is that one lacks an independent criterion for judging whether the alleged primary accent (i.e. the accent designated as such by the algorithm) is indeed the 'real' one.

Essentially, however, the primary-secondary distinction is not an issue in my approach. The fact that in every utterance there is an accent that can be traced back to the top node does not imply that that accent is the one that somehow 'belongs to' the top node. It merely expresses the insight that every utterance should get an accent (at least one, that is). The accent on dollars in (1a), for instance, comes from the top node, but so does the one on thousand in (1b), not because it would signal 'broad focus', but because it is the only possible landing site for an accent that remains: dollars has been deaccented by the discourse grammar and the utterance as a whole should get an accent all the same.

\subsection{Potential problem cases}

\section{Deaccented NP within PP}

If an NP within a PP is deaccented (e.g. by the discourse grammar), then Actual weak-strong labeling turns the order $\omega-\varsigma$ into $\mathrm{s}-\mathrm{w}$ and consequently, Accenting assigns an accent to $\mathrm{P}$. This is alright if $\mathrm{P}$ is a 'lexical' (i.e. meaningful) preposition, like achter ('behind'), na ('after'), naast ('beside') voor ('in-front-of'), voor $_{2}$ ('before'), but not if it is a 'functional' preposition (i.e. one that acts mainly as a case marker), like aan ('to'), met ('with'), van ('of'), voor 3 ('for'). An obvious solution is to mark functional prepositions $[-\mathrm{A}]$ in the lexicon. Then both $\mathrm{P}^{0}$ and the complement NP are $[-\mathrm{A}]$, hence the whole PP becomes deaccented (by upward passing of the $[-\mathrm{A}]$ attribute), and accent will shift to the PP's sister. So, hij houdt van MARIE ('he loves Marie') becomes hij HOUDT van d'r ('he loves her') and hij zorgt voor MARIE ('he takes care of Marie') becomes hij zORGT voor d'r ('he takes care of her'), but hij zit naast MARIE ('he sits beside Marie') becomes hij zit NAAST d'r ('he sits beside her') and hij ging voor MARIE staan ('he stepped in front of Marie') becomes hijging vOoR d'r staan ('he stepped in front of her').

\section{DP-analysis}

In this paper, determiners are analysed as NP specifiers. Consequently, being weak XPs, they get accented, unless they are marked $[-\mathrm{A}]$ in the lexicon. This is the desired result, for many determiners (numerals, quantifiers, etc.) should indeed get an accent, and the ones that should not (e.g. articles) have to be marked $[-\mathrm{A}]$ anyway, in order to avoid them from getting accented as a result of accent shift (just like the functional prepositions discussed above). If determiners are analysed as 
heads of DP $\left(\mathrm{D}^{0} \mathrm{~s}\right)$ instead, we get the wrong result: determiners will not get accents (unless as a result of accent shift).

\section{Adjective with a complement}

For sentences like $i k$ ben het gezeur beu ('I am the nagging sick-of') and $i k$ ben dol op spruitjes ('I am fond of sprouts'), SAiD produces only one of the two desired accents, namely the one on the complement. The additional accent on the adjective cannot be obtained. So, one of two things must be the case: (1) the hypothesis concerning the $\varsigma$-hood of complements in X-bar trees has to be rejected, or at least adjusted, or (2) the NP/PP in the construction under discussion is in fact not a complement. To cut a long story short: in Zwart (1993) it is convincingly argued that in Dutch, NP and PP are "not in the basic complement position inside AP", but are adjoined to AP instead. Ample evidence is presented, among which the following data: het gezeur meer dan beu ('the nagging more than sick-of') versus ${ }^{*}$ meer dan het gezeur beu ('more than the nagging sick-of') zo trots als een pauw op zijn auto ('as proud as a peacock of his car') versus ?zo trots op zijn auto als een pauw ('as proud of his car as a peacock'), and de op zijn auto nog altijd erg trotse man ('the of his car still always very proud man') versus * de nog altijd erg op zijn auto trotse man ('the still always very of his car proud man'). If Zwart's analysis is correct, then (2) is the correct option: the NP/PP is an adjunct, hence weak-by-default, and thus the lower AP is strong-by-default. So, the adjective gets its accent from the top node (via the lower AP) and the noun from the weak NP/PP:
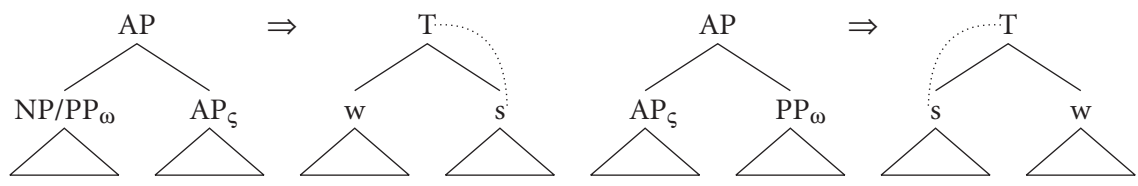

\section{On integrative accent}

\subsection{Baart's approach}

In Baart's theory (and hence in Pros2 as well) subjects are strong-by-default because they get the (only) accent in case of integrative sentence accent. In other words, if it is possible to focus an entire sentence by means of a single accent, then this accent is on the subject. However, in Baart's algorithm integrative accent on the subject is only assigned in sentences that consist of just a subject and a verb. As soon as there is an additional object or AP/PP complement, this gets its own accent, NP and AP being candidates for focus on their own. In other words, of the following sentences, which all allow for integrative accent, only (6a) is actually accented as 
such; (6b-d) get additional accents on ziek ('ill'), trap ('stairs') and ongeluk ('accident'), respectively.

(6) a. (Sst) JAN slaapt/sLAAPt!

ssh Jan sleeps

'(Ssh) Jan's asleep!'

b. MARIE is ziek/ziek!

Marie is ill

'Marie's ill!'

c. JAN heeft een ongeluk/ongeLuK gehad!

Jan has an accident had

'Jan's had an accident!'

d. JAN is van de trap/TRAP gevallen! Jan has down the stairs fallen

'Jan's fallen down the stairs!'

Pros2, integrative accent on the subject is never actually assigned at all, because the VP as well is a candidate for focus.

Mutatis mutandis the same goes for the VP level: both in Baart's algorithm and in Pros2, the left-hand argument in a VP that is headed by a ditransitive verb (and as such contains two arguments) is strong-by-default, because it gets the (only) accent in case of integrative VP accent. In practice, however, only VPs headed by a monotransitive verb get integrative accent: if there is more than one argument, each one gets its own accent, as in

(7) (hij heeft) een POLITIEMAN een klap/KLAP verkocht.

he has a policeman a blow dealt

'he dealt a policeman a blow.'

So, in none of the two algorithms does a VP headed by a ditransitive verb ever actually get integrative accent. This is odd for a theory in which integrative accent is supposed to be a key concept.

\subsection{Integrative accent in SAiD}

As subjects and left-hand arguments, being specifiers of IP and VP, respectively, are weak-by-default in my approach, SAiD produces the two-accents versions in all cases of (6)-(7), just like Pros2. However, my approach has both theoretical and practical advantages over the Baart/Pros2 approach. Firstly, specifiers get a uniform treatment: a specifier of $\mathrm{I}^{1}$ gets the same labeling as a specifier of $\mathrm{N}^{1}$, for example. Secondly, in SAiD there is no discrepancy between the concept behind the algorithm and its output. Thirdly, integrative sentence/VP accent is both optional and marked, which is acknowledged in my approach. And finally, the practical advantage of SAiD is that integrative sentence/VP accent can be obtained in a simple and natural way. 
As to the optionality and markedness of integrative sentence/VP accent: the optionality was already illustrated in (6)-(7), which all allow both for the versions with one accent and those with two. Only in the case of a support verb (a verb that is not used in one of its independent meanings, but whose meaning depends on its nearest argument) may integrative accent be obligatory, as in De TELEFOON gaat! ('The phone's ringing!'). ${ }^{4}$ In most cases, however, integrative accent is not even allowed, as in JAN heeft m'n FIETS/" fiets gemaakt ('Jan fixed my bike'), and in (5a). In other words: integrative accent is not only optional, but also marked, in the sense that its use is limited. ${ }^{6}$

How is integrative sentence/VP accent obtained in SAiD? This is simple: we only have to assume a rule that translates the default order $\omega-\varsigma$ of the IP/VP node into the actual order s-w under certain conditions. The fact that in SAiD only (the top node and) weak XPs are accented takes care of the rest, as is illustrated by the examples (8)-(9) below.

(8) JAN heeft een ONGELUK/ongeluk gehad!

Jan has an accident had 'Jan's had an accident!'

(9) (We gaan) омA naar HUIs/huis brengen. we go grandma to house take '(We are going to) take grandma home.'

On the left are the pruned X-bar trees with $\omega$ - $\varsigma$ labeling, in the middle the metrical trees with unmarked accentuation, and on the right the metrical trees with integrative accent.

(8)
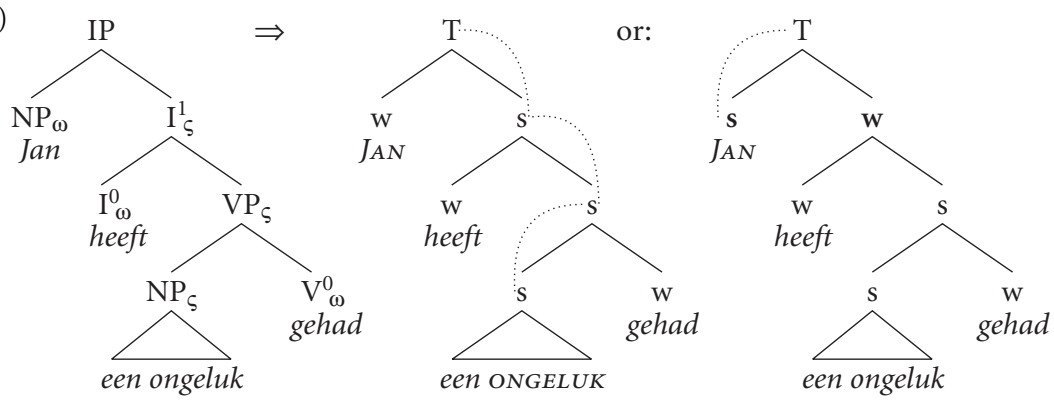

The differences between the marked and the unmarked version are all retraceable to the different $\mathrm{w}$-s labelings of the IP node ( $\mathrm{w}$-s in the unmarked, s-w in the marked version). In the unmarked version the subject NP, being weak, gets its own accent. The object NP gets its accent from the IP node, via a chain of strong nodes. In the marked version (the one with integrative sentence accent) the subject NP, being strong, gets its accent from the IP node. The object NP is strong as well, but 
it is not accented, as the upper boundary of the chain of strong nodes dominating it is the (weak) $\mathrm{I}^{1}$, which is not a maximal projection and is therefore not accented.

(9)

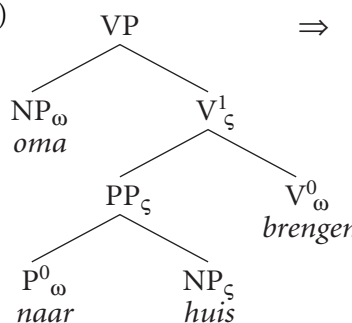

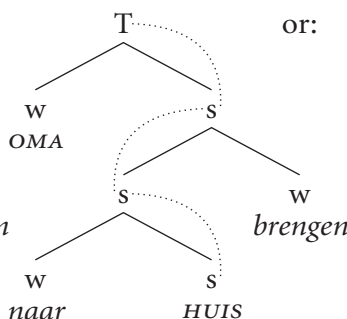

or:

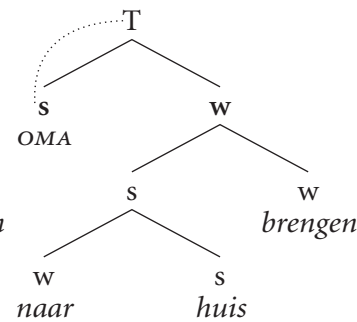

In (9), as in (8), the different accentuations are retraceable to the different w-s labelings of the top node (in this case the VP), as the reader can check for himself.

In order to see that a rule to the effect that the default order $\omega-\varsigma$ of an IP/VP node is translated into the actual order $s-\mathrm{w}$ under certain conditions is not only a simple, but also a natural way to account for integrative accent, one has to realize that the $\mathrm{VP} / \mathrm{V}^{1}$ involved functions as a complex predicate (a phenomenon sometimes referred to as 'semantic integration'): oma naar huis brengen ('take grandma to house') in (9), for instance, is equivalent to oma thuisbrengen ('take-home grandma') and een politieman een klap verkopen ('deal a policeman a blow') in (7) to een politieman slaan ('hit a policeman'). Now, intuitively, oma and een politieman act as the complement of the complex $\mathrm{V}$ naar-huis-brengen and een-klap-verkopen, respectively, rather than as the specifier of the $\mathrm{V}^{1}$. This justifies that the left-hand argument is labeled strong instead of weak in such a case. A similar argumentation applies to the sentence level.

Paradoxically enough, in the Baart/Pros2 approach integrative accent cannot be obtained in a simple and natural way. ${ }^{7}$

\section{Conclusion}

In this paper I have tried to answer the question: given that an $(y)$ utterance must be accented, where do we place accent? My answer to this question is SAiD, an algorithm for the assignment of sentence accents in Dutch, which takes as input pruned X-bar S-structures enriched with deaccenting information (coming from the lexicon and from a discourse grammar), the main idea behind it being that accenting is a surface-syntactic affair and deaccenting a matter of context. 


\section{Notes}

* I thank Kees Vermeulen and an anonymous reviewer for their valuable comments on an earlier version of this paper.

1. 'Sentence accent' (also named 'sentence-level' or 'postlexical' accentuation) applies to phrases or utterances as a whole, as opposed to 'word accent', which is determined in the lexicon.

2. A text-to-speech system is a computer program that converts a written text into a spoken version of that text.

3. Note that it is only the position of sentence accents that is claimed to be a matter of surface syntax. There is reason to assume that accent types, i.e. types of pitch movements or pitch movement configurations, are context-dependent.

4. That the Dutch verb gaan is a support verb is nicely illustrated by the fact that one cannot translate gaan into English independently of the NP de telefoon (there is no reading of gaan that has to ring as its English translation).

5. The symbol '\#' should be read as 'infelicitous', i.e. unacceptable in the given context (in this case rather: lack of context). As an answer to the question Who fixed your bike?, for instance, JAN heeft m'n fiets gemaakt would not be infelicitous.

6. The use is not only limited to certain types of predicates (verbs, $\mathrm{V}^{1} \mathrm{~s}, \mathrm{VPs}$ ), but also to certain types of (subject/left-hand-argument) NPs. Furthermore the utterance as a whole must be speaker-oriented or otherwise relevant for the 'conversational situation'.

7. It would lead too far afield to explain here how exactly integrative accent could be obtained in the Baart/Pros2 approach. Suffice it to say that it would require that parts of the utterance be left out of focus, which would imply an internal contradiction, integrative accent being about 'allfocus' constructions. Another drawback is that integrative sentence accent and integrative VP accent would require different rules.

\section{References}

Baart, J. (1987) Focus, Syntax and Accent Placement. Diss. Leiden University.

Bolinger, D. L. (1972) 'Accent is Predictable (If you're a Mind-Reader)'. Language 48, 633-644.

Chomsky, N. (1986) Barriers. MIT Press, Cambridge, Mass.

Cinque, G. (1993) 'A Null Theory of Phrase and Compound Stress'. Linguistic Inquiry 24, 239-297.

Dirksen, A. and H. Quené (1993) 'Prosodic Analysis: The Next Generation'. In V.J. van Heuven and L. Pols, eds., Analysis and Synthesis of Speech: Strategic Research towards High-Quality Text-to-Speech Generation. Mouton de Gruyter, Berlin.

Fuchs, A. (1976) ' 'Normaler' und 'Kontrastiver' Akzent'. Lingua 38, 293-312.

Gussenhoven, C. (1984) On the Grammar and Semantics of Sentence Accents. Foris Publications, Dordrecht.

Ladd, D. R. (1980) The Structure of Intonational Meaning. Indiana University Press, Bloomington.

Ladd, D.R. (1996) Intonational Phonology. Cambridge Studies in Linguistics 79. Cambridge University Press.

Lambrecht, K. (1994) Information Structure and Sentence Form. Topic, Focus and the Mental Representations of Discourse Referents. Cambridge Studies in Linguistics 71. Cambridge University Press. 
Liberman, M. and A.S. Prince (1977) 'On Stress and Linguistic Rhythm'. Linguistic Inquiry 8, 249-336.

Pierrehumbert, J. (1980) The Phonology and Phonetics of English Intonation. PhD thesis MIT, published 1988 by IULC.

Pinto, M. (1997) Licensing and Interpretation of Inverted Subjects in Italian. Diss. Utrecht University.

Schmerling, S. F. (1976) Aspects of English Sentence Stress. University of Texas Press, Austin. Selkirk, E. (1986) 'On Derived Domains in Sentence Phonology'. Phonology 3, 371-405.

Zwart, C. J. W. (1993) Dutch Syntax: A Minimalist Approach. Groningen Dissertations in Linguistics 10. 